\title{
Prevalence of sexually transmitted infections among pregnant women with known HIV status and their perinatal outcome- a retrospective single centre analysis
}

\author{
Supriya Chaubey ${ }^{1}$, Ragini Melhotra ${ }^{2}$, Umesh Sharma ${ }^{1 *}$
}

\author{
${ }^{1}$ Department of Obstetrics and Gynecology, ABVIMS and Dr. RML Hospital, New Delhi, India \\ ${ }^{2}$ Department of Obstetrics and Gynecology, MLN Medical College, Allahabad, Uttar Pradesh, India
}

Received: 06 February 2021

Accepted: 09 March 2021

\section{*Correspondence: \\ Dr. Umesh Sharma, \\ E-mail: drumeshkgmc@gmail.com}

Copyright: $\odot$ the author(s), publisher and licensee Medip Academy. This is an open-access article distributed under the terms of the Creative Commons Attribution Non-Commercial License, which permits unrestricted non-commercial use, distribution, and reproduction in any medium, provided the original work is properly cited.

\begin{abstract}
Background: The objective of this study was to determine the prevalence of sexually transmitted infections (STIs) and other reproductive tract infections (RTIs) among pregnant women and their perinatal outcome.

Methods: Pregnant women in their $3^{\text {rd }}$ trimester $(\mathrm{N}=1000)$ from September 2009 and august 2010 were included. Information related to demographic profile, obstetrics complications, previous genital infections and gynecological diseases were taken. All pregnant women were followed up for their 4-week perinatal outcome.

Results: The prevalence of sexually transmitted infection was $25.2 \%$ in pregnant women. The prevalence of HIV, Hepatitis B, HSV2 and HPV infection was $2.3 \%, 4.2 \%, 0.6 \%, 0.1 \%$ respectively. Prevalence of infection with $C$. trachomatis, G. vaginalis, T. vaginalis and C. albicans was 5.8\%, 10.2\%, 5.2\%, 9.5\% respectively. The prevalence of infection with $N$. gonorrhea and $T$. pallidum was found to be 0 .

Conclusions: Rates of STIs and RTIs are still high among pregnant women. A declining trend for curable STIs/RTIs (syphilis and gonorrhea) was noted. Perinatal outcome was affected adversely in pregnant women with STIs/RTIs.
\end{abstract}

Keywords: HIV status, Mixed STIs, Non-viral STIs, STI in pregnancy, Viral STIs

\section{INTRODUCTION}

The prevalence of STIs/RTIs has been shown to vary from one country to another and among different group within the same country. According to WHO global estimates for 2016, there were roughly 376 million new infections of the four curable STIs- chlamydia, gonorrhoea, syphilis and trichomoniasis. ${ }^{1}$ The scale of the STIs/RTIs problem is too great to be dealt with in specialized STIs/RTIs centres alone, and steps must be taken to expand and integrate STIs/RTIs management in primary health and other health centres. The emerging links between STIs/RTIs and adverse pregnancy outcome offer exciting possibilities for prevention of these sequels through primary and secondary prevention of both STIs/RTIs before and during pregnancy. Therefore, a public awareness and education about these infections and methods of preventing them is important. Demographic and epidemiological knowledge of STIs/RTIs by periodically monitoring the prevalence of etiological agents is useful in guiding clinical management of these patients.

\section{METHODS}

Retrospective data of all pregnant females in their third trimester, who had attended the outpatient department and/or admitted in indoor and emergency ward of Department of Obstetrics and Gynecology in a tertiary care hospital over a period of 12 months (2009-2010), were included. Data regarding their age, education, occupation, socioeconomic status, habitat, marital status, parity, contraceptive practice, previous pregnancies, pregnancy complications, pervious history of sexually 
transmitted infections/reproductive tract infections and any treatment taken for it were taken out from the hospital records. Search also included any evidence of vulval lesion, cervical erosion and discharge from vagina and any other information related to gynecological diseases if at all available.

\section{Inclusion criteria}

Discharge per vaginum, vaginal itching, burning micturition, lower abdominal pain and back pain, fever, extreme fatigue, rapid weight loss, blister or open sores on vagina and perineal region, headache and muscle aches, yellowish discoloration of conjunctiva and skin.

After applying the above inclusion criteria's, 1000 consecutive patients were included in this study and their 4-week perinatal outcome were noted. As per institutional policy diagnosis of HIV1 and 2 was done by ELISA. HPV infection was diagnosed by Hybrid Capture II technique. Chlamydia infection and HSV infection is based on clinical findings and ELISA. Tzanck smear analysis is done as supportive diagnostic method for HSV infection. Presence of actively motile Trichomonas under microscope in Hanging drop preparation of vaginal secretions was used to diagnosed $T$. vaginalis. $\mathrm{KOH}$ mount was used to diagnosed Candida, which confirmed by culture on Saboraud's glucose agar medium. Gardnerella was diagnosed by Amsel's criteria. Gonorrhoea was diagnosed by clinical findings and Gram's staining which confirmed by culture on chocolate agar. Venereal disease research laboratory (VDRL) test and Treponema pallidum hemagglutination (TPHA) assay are performed for diagnosis of syphilis.

Patients were divided into two groups (1 and 2) according to presence or absence of STIs/RTIs. Group 1 consisted of 252 women having STIs/RTIS and group 2 consisted of 748 women not having any STIs/RTIs.

\section{RESULTS}

Number of sexually transmitted infections/reproductive tract infections in studied pregnant women (1000) was $252(25.2 \%)$. In group 1, $162(63.88)$ were from lower socioeconomic status. In group 2 maximum number of pregnant women $370(49.46 \%)$ were from middle socioeconomic status. The difference between both the groups was found to be statistically significant. In group 1 , maximum number of women $192(76.21 \%)$ were rural dwellers. In group 2, $392(52 \%)$ women were of rural dwellers. The difference was found to be statistically significant $(p=0.0001 ; p=0.05)$. The number of hepatitis B virus, HIV 1, HSV 2 and HPV infection in studied pregnant women were found to be 42 (4.2\%), 23 (2.3\%), $6(0.6 \%)$ and $1(0.1 \%)$ respectively. The percentage of $G$. vaginalis infection was found to be $10.2 \%$ (102 cases) in total study population. The percentage of $C$. albicans, $C$. trachomatis and $T$. vaginalis infection were 9.5\% (95 cases), $5.8 \%$ (58 cases) and 5.2\% (52 cases) respectively.
In the present study there was 128 pregnant women having mixed infections. Maximum 29 (22.66\%) pregnant women had mixed infection with $C$. albicans and $G$. vaginalis. In this study curable sexually transmitted diseases like gonorrhoea and syphilis were not found. All the above results have been depicted in various (Tables 1-3).

Table 1: Socioeconomic status of pregnant females with (group 1) and without (group 2) STIs/RTIs.

\begin{tabular}{|c|c|c|c|}
\hline $\begin{array}{l}\text { Socioeconomic } \\
\text { status of study } \\
\text { participants }\end{array}$ & $\begin{array}{l}\text { Group } 1 \\
n=252 \\
(100 \%)\end{array}$ & $\begin{array}{l}\text { Group } 2 \\
n=748 \\
(100 \%)\end{array}$ & $\begin{array}{l}\mathbf{P} \\
\text { value }\end{array}$ \\
\hline Upper class & $23(9.1)$ & 154 (20.6) & \multirow{3}{*}{$<0.001$} \\
\hline Middle class & $67(26.6)$ & $370(49.5)$ & \\
\hline Lower class & $162(64.3)$ & $224(29.9)$ & \\
\hline
\end{tabular}

STI: Sexually transmitted infection

Table 2: Pathogen causing infection in pregnant females with sexually transmitted infection.

\begin{tabular}{|ll|}
\hline $\begin{array}{l}\text { Sexually transmitted } \\
\text { infection }\end{array}$ & $\begin{array}{l}\text { Number of patients } \\
\text { (percentage) } \mathbf{n}=\mathbf{2 5 2} \\
(\mathbf{1 0 0 \%})\end{array}$ \\
\hline $\begin{array}{l}\text { Human immunodeficiency } \\
\text { virus 1 }\end{array}$ & $23(9.1)$ \\
\hline Hepatitis B & $42(16.7)$ \\
\hline Herpes simplex virus 2 & $6(2.4)$ \\
\hline Human papilloma virus & $1(0.4)$ \\
\hline Chlamydia trachomatis & $58(23)$ \\
\hline Neisseria gonorrhoea & $0(0)$ \\
\hline Gardnerella vaginalis & $102(40.5)$ \\
\hline Trichomonas vaginalis & $52(20.6)$ \\
\hline Candida albicans & $95(37.7)$ \\
\hline Treponema pallidum & $0(0)$ \\
\hline
\end{tabular}

Among 23 HIV seropositive pregnant women, 1 (4.34\%) pregnant woman had HSV-2 infection, 2 (8.69\%) pregnant women had C. albicans infection and $2(8.69 \%)$ pregnant women had $G$. vaginalis infection. Among rest 229 pregnant women, who were HIV seronegative but having other STIs, 5 (2.1\%) had HSV-2 infection, 60 (26.20\%) had C. albicans infection and $100(43.67 \%)$ pregnant women had $G$. vaginalis infection. The difference between both groups for HSV-2 and $C$. albicans infection were not significant. The difference between both groups for $G$. vaginalis was significant (Tables 4 and 5). Out of 252 pregnant women of group 1 , 224 women were followed up. In group 2 out of 748 pregnant women, 672 were followed up. Perinatal outcome of the group was compared. This study showed statistically significant difference between preterm deliveries $(\mathrm{p}=0.0001)$, intra uterine foetal demise $(\mathrm{p}=0.002)$ and low birth weight $(\mathrm{p}=0.007)$. It was concluded that perinatal outcome was affected adversely in pregnant women with STIs as compared to the pregnant women without STIs. All the above results have been depicted in various (Tables 4 and 5). 
Table 3: Mixed infections in pregnant females with sexually transmitted infections.

\begin{tabular}{|ll|}
\hline Pathogen causing infection & Number of patients (percentage $\mathbf{n = 2 5 2}(\mathbf{1 0 0 \% )}$ \\
\hline Infection by one organism & $124(49.2)$ \\
\hline Chlamydia trachomatis + Trichomonas vaginalis & $12(4.8)$ \\
\hline Chlamydia trachomatis + Gardnerella vaginalis & $26(10.3)$ \\
\hline Gardnerella vaginalis + Trichomonas vaginalis & $20(7.9)$ \\
\hline Candida albicans + Gardnerella vaginalis & $29(11.5)$ \\
\hline Chlamydia trachomatis + Candida albicans & $13(5.2)$ \\
\hline Trichomonas vaginalis + Candida albicans & $10(4)$ \\
\hline HIV 1 and 2 + HSV 1 and 2 & $1(0.4)$ \\
\hline HIV 1 and 2 + Gardnerella vaginalis & $2(0.8)$ \\
\hline HIV 1 and 2 + Candida albicans & $2(0.8)$ \\
\hline Hepatitis B + Trichomonas vaginalis & $3(1.2)$ \\
\hline Hepatitis B + Gardnerella vaginalis & $6(2.4)$ \\
\hline Hepatitis B + Candida albicans & $4(1.6)$ \\
\hline
\end{tabular}

HIV:Human immunodeficiency virus; HSV: herpes simplex virus

Table 4: Pregnancy outcome in pregnant females with (group 1) and without STI (group 2).

\begin{tabular}{|llll|}
\hline *Pregnancy outcome & Group $\mathbf{1} \mathbf{n = 2 2 4}(\mathbf{1 0 0} \%)$ & Group $\mathbf{2}$ & P value \\
\hline No adverse outcome & $28(12.5 \%)$ & $448(66.7 \%)$ & 0.0001 \\
\hline Pre term delivery & $102(45.5 \%)$ & $52(7.7 \%)$ & 0.0001 \\
\hline Intrauterine death & $59(26.3 \%)$ & $112(16.7 \%)$ & 0.002 \\
\hline Low birth weight & $35(15.6 \%)$ & $60(8.9 \%)$ & 0.007 \\
\hline
\end{tabular}

*Follow up data was available in 224/252 patients in group 1 and 672/ 748 participants of group 2; STI: Sexually transmitted infection

Table 5: Comparison of STI in HIV seropositive and HIV seronegative pregnant women.

\begin{tabular}{|c|c|c|c|c|c|c|}
\hline \multirow{2}{*}{ Pathogen } & \multicolumn{2}{|c|}{ HIV seropositive } & \multicolumn{2}{|c|}{ HIV seronegative } & \multirow[t]{2}{*}{$\chi^{2}$} & \multirow[t]{2}{*}{$P$ value } \\
\hline & No. & Percentage & No. & Percentage & & \\
\hline HSV 2 & 1 & 4.34 & 5 & 2.1 & 0.421 & 0.516 \\
\hline C. albicans & 2 & 8.69 & 93 & 41.61 & 2.573 & 0.1087 \\
\hline G. vaginalis & 2 & 8.69 & 100 & 43.668 & 9.208 & 0.0024 \\
\hline
\end{tabular}

\section{DISCUSSION}

Sexually transmitted infections (STIs)/reproductive tract infections (RTIs) are a major public health problem. STIs and other reproductive tract infections (RTIs) have been associated with several adverse pregnancy outcome including abortions, still birth, preterm delivery, low birth weight, postpartum sepsis, neonatal pneumonia, neonatal blindness and congenital infections. ${ }^{2}$

In this study the percentage of STIs in studied pregnant women was $25.2 \%$, similar findings were reported by Karim et al who studied 55974 pregnant women and found the prevalence of STIs to be $24.9 \% .{ }^{3}$ Mwakagile et al reported higher prevalence of STIs in pregnant women $41.2 \% .^{4}$ They included the pregnant women of Dar-eSalaam, Tanzania in their study and found that prevalence of STIs in African countries is much higher and the pregnant women studied were at or near term. More recent data from routine screening in antenatal care settings in sub-Saharan Africa have shown prevalence of common STIs, including chlamydia, gonorrhoea, and syphilis, to be as high as $15 \% .^{5,6}$

The high percentage of STIs/RTIs in pregnant women of lower socioeconomic status coming from rural areas were probably because of low literacy rate, early age of marriage, difficult or no access to health care facilities, poor hygiene and social abuse, William's et al also reported the higher incidence of STI/RTI in women from lower income group. ${ }^{7}$

In this study 128 pregnant women $(12.8 \%)$ had mixed infections. William et al showed, $3.3 \%$ pregnant women having $\geq 1$ curable STD. ${ }^{7}$ Non-viral infection was found in $70(26.59 \%)$ pregnant women and $54(21.42 \%)$ women were positive for viral infections. The finding of present study was like findings of Mwakagile et al who reported $41.2 \%$ prevalence of non-viral infection and $30.3 \%$ prevalence of mixed infections. ${ }^{4}$ Among viral infections (72 out of 252 cases) maximum $42(58.33 \%)$ pregnant women had hepatitis B virus infection. 
Out of 252, 23 (31.94\%) women were seropositive for HIV 1 infection. The percentage in total was $2.3 \%$. The present study was comparable to the study of Msuya et al who reported the prevalence of HIV seropositive pregnant women as $6.9 \% .^{8}$ These findings were higher than present study and might be due to the reason that the study was conducted in medium-high prevalence zone for HIV and it has larger study population as compared to present study. Mwakagile et al found the prevalence of HIV seropositive pregnant women to be $12.2 \% .^{4}$ The study group was from Dar-e-Salaam, Tanzania, and Africa. The prevalence was much higher than present study because of higher prevalence of HIV infection in African countries. Similar findings were also found by Blank hart et al. ${ }^{9}$ Chloe et al reported HIV incidence to be 3.8 per 100 per year. ${ }^{10}$ Other two studies conducted in Uganda and Zimbabwe (2004-2007) had incidence between 1.6 and 2.3/100 per year. ${ }^{11,12} \mathrm{~A}$ much higher incidence had been shown in a study conducted across seven African countries which found 7.4/100 per year (2004 2007). ${ }^{13}$

In present study $8.33 \%$ pregnant women in group 1 had infection with HSV 2. Rathore et al found the seroprevalence of HSV 2 infection in pregnant women as $7.5 \% .{ }^{14}$ Msuya et al found higher prevalence $33.6 \%$ for HSV-2 infection. ${ }^{8}$ In present study only one pregnant woman had HPV infection. The total percentage was $0.1 \%$.

In the present study the percentage of C. trachomatis infection among all STI/RTIs was found to be $5.8 \%$. Blank hart et al also found the prevalence of $C$. trachomatis as $6.2 \% .^{9}$ In present study the percentage of T. vaginalis was $5.2 \%$. Similar findings were also stated by Blank hart et al. ${ }^{9}$ They found the prevalence as $9.9 \%$. Mwakagile et al found prevalence of $T$. vaginalis to be $22.7 \%$, which is much higher, and this might be due to high prevalence of STIs in African countries. ${ }^{4}$

In this study none were having gonorrhoea. Mwakagile et al and Blank hart et al reported prevalence of $3.6 \%$ and $3.1 \%$ respectively for gonorrhoea. ${ }^{4,9}$ The disease may still be prevalent in some areas of Africa. Similarly, syphilis was not found in any women in the present series. Mwakagile et al and Blank hart et al found the prevalence of syphilis to be $4.0 \%$ and $6.7 \%$ respectively. ${ }^{4,9}$ In present study 3 pregnant women were found to be VDRL positive. One woman was lost during follow up and in rest 2 women TPHA test was found to be negative. Meaning thereby 2 women had false VDRL positive test. The VDRL test report may be falsely positive during pregnancy. Many recent studies that used either clinicianverified diagnoses or data from settings serving higherrisk populations (e.g. STD clinics) showed incidence of chlamydia $(2.2-13.8 \%)$, gonorrhoea $(1.2-7.1 \%)$, syphilis $(1.2 \%)$, and trichomoniasis $(8.9-14.9 \%){ }^{15-20}$

In the present study 102 pregnant women were infected with $G$. vaginalis and the percentage was $10.2 \%$ in total studied women. Blank hart et al reported the prevalence of bacterial vaginosis as $29.1 \%$ in 481 pregnant women. ${ }^{9}$ The higher prevalence was since majority of women had specific clinical symptoms related to STIs. Kekki et al detected higher prevalence of bacterial vaginosis 10$30 \% .{ }^{21}$ In above mentioned studies there were differences in protocols, study size, inclusion criteria and geographical areas. Therefore, results could not be compared on true grounds.

In present study 95 pregnant women had infection with C. albicans and the percentage was $9.5 \%$ in total. Cotch et al studied 13,914 pregnant women and reported the prevalence of infection with $C$. albicans to be $10.0 \% .^{22}$ Blank hart et al reported a much higher prevalence of $C$. albicans as $46.6 \% .^{9}$ They included pregnant women with clinical symptoms of STIs. This might be the reasons for the higher prevalence of candida infection in these studies.

Out of 252 pregnant women found positive for STIs, 224 pregnant women were followed up. Among 748 pregnant women, found to be negative for STIs, 672 were followed up and the perinatal outcome between two groups compared. In group 1 there were $102(45.53 \%)$ women with preterm deliveries, $59(26.3 \%)$ women had intrauterine foetal demise and 35 (15.63\%) women had delivered low birth weight babies. Normal perinatal outcome was found in $28(12.5 \%)$ pregnant women. In group 2 out of 672 pregnant women $52(7.74 \%)$ women had delivered preterm babies, $112(16.67 \%)$ pregnant women had intrauterine foetal demise and 60 (8.9\%) women delivered low birth weight babies. Normal perinatal outcome was found in $448(66.67 \%)$ pregnant women. The difference between both the groups was found to be statistically significant for normal perinatal outcome $(p=0.0001)$, preterm delivery $(p=0.0001)$, low birth weight babies $(\mathrm{p}=0.007)$ and intrauterine foetal demise $(\mathrm{P}=0.002)$ (Table 4$)$. In group 2 number of IUDs were high because majority of the patients were referred cases with obstetrical complications and morbidity. Studies of previous authors also showed the association between various STIs and adverse pregnancy outcome. Andrews et al also reported women with $C$. trachomatis infection at 24 weeks' gestation were 2 times as likely as uninfected women to have a spontaneous preterm birth at $<37$ weeks' gestation (odds ratio, 2.2; 95\% confidence interval, 1.03-4.78) and 3 times as likely to have a spontaneous preterm birth at $<35$ weeks' gestation (odds ratio, 3.2; 95\% confidence interval (1.08-9.57). ${ }^{23}$

Kekki et al reported that bacterial vaginosis was associated with preterm uterine contractions in 42 $(24.85 \%)$ cases and premature rupture of membrane in 80 $(47.33 \%)$ cases out of 169 pregnant women. ${ }^{21}$ Herbert et al studied and screened 4,429 pregnant women and reported that in the intervention group the number of preterm births were significantly lower than the control group $(3.01 \%$ versus $5.3 \%)(\mathrm{p}=0.0001)$ and concluded that integrating a simple infection screening programme 
into antenatal care leads to a significant reduction in preterm births. ${ }^{24}$

In this study population, it was found that presence of STIs in pregnant women were associated with adverse perinatal outcome. Due to presence of STIs there were increased chances of preterm rupture of membranes, preterm labour, chorioamnionitis, intra uterine foetal demise and low birth weight, which leads to adverse perinatal outcome, increasing perinatal morbidity and mortality. "Many STIs/RTIs may remain asymptomatic. Hence might have missed many cases by recruiting only patients who manifested specific symptoms as study participants. Study conducted in a referral hospital, not reflecting the status of the STIs among pregnant females in the community is another limitation. Lack of information on factors like hypertension, diabetes mellitus, anaemia and nutritional status of pregnant females that can lead to adverse outcome in pregnancy is another limitation, especially since most of the pregnant women with STIs belonged to low socioeconomic status".

\section{CONCLUSION}

This study showed that STIs/RTIs were more prevalent among pregnant women from rural and lower socioeconomic status. It was found that HIV seropositive pregnant women had similar prevalence of STIs as HIV seronegative pregnant women. Also, prevalence of nonviral STIs/RTIs were found to be higher than viral STIs/RTIs. The occurrence of gonorrhoea and syphilis was found to be zero in the study. We made a diagnosis of STI/RTI in $25.2 \%$ of 1000 pregnant females who showed symptoms suggestive of the former. STI in pregnancy showed a statistically significant association with intrauterine death, preterm delivery and delivery of low-birth-weight babies. Prospective studies in pregnant women that are designed to collect information on factors that can result in adverse pregnancy outcomes (including STIs/RTIs) may improve our understanding on the effect of maternal STIs on outcome of pregnancy.

Funding: No funding sources

Conflict of interest: None declared

Ethical approval: The study was approved by the Institutional Ethics Committee

\section{REFERENCES}

1. WHO Report on global sexually transmitted infection surveillance, 2018. Available from: https://apps.who.int/iris/bitstream/handle/10665/277 258/9789241565691-eng.pdf. Accessed on 22 December 2020

2. Mullick S, Watson-Jones D, Beksinska M, Mabey D. Sexually transmitted infections in pregnancy: prevalence, impact on pregnancy outcomes, and approach to treatment in developing countries. Sex Transmit Infect. 2005;81(4):294-302.
3. Wilkinson D, Karim SA, Harrison A, Lurie M, Colvin M, Connolly C, et al. Unrecognized sexually transmitted infections in rural South African women: a hidden epidemic. Bull World health Organ. 1999;77(1):22.

4. Mwakagile D, Swai AB, Sandström E, Urassa E, Biberfeld G, Mhalu FS. High frequency of sexually transmitted diseases among pregnant women in Dar es Salaam, Tanzania: need for intervention. East Afr Med J. 1996;73(10):675-8.

5. Menendez C, Castellsague X, Renom M, Sacarlal J, Quinto L, Lloveras B, et al. Prevalence and risk factors of sexually transmitted infections and cervical neoplasia in women from a rural area of southern Mozambique. Infect Dis Obstet Gynecol. 2010;2010:609315.

6. Chico RM, Mayaud P, Ariti C, Mabey D, Ronsmans C, Chandramohan D. Prevalence of malaria and sexually transmitted and reproductive tract infections in pregnancy in sub-Saharan Africa: a systematic review. JAMA. 2012;307(19):2079-86.

7. Williams CL, Harrison LL, Llata E, Smith RA, Meites E. Sexually transmitted diseases among pregnant women: 5 states, United States, 2009-2011. Matern Child Health J. 2018;22(4):538-45.

8. Msuya SE, Uriyo J, Hussain A, Mbizvo EM, Jeansson S, Sam NE, et al. Prevalence of sexually transmitted infections among pregnant women with known HIV status in northern Tanzania. Reprod Health. 2009;6(1):1-8.

9. Blankhart D, Müller O, Gresenguet G, Weis P. Sexually transmitted infections in young pregnant women in Bangui, Central African Republic. Int $\mathbf{J}$ STD AIDS. 1999;10(9):609-14.

10. Teasdale CA, Abrams EJ, Chiasson MA, Justman J, Blanchard K, Jones HE. Incidence of sexually transmitted infections during pregnancy. PLoS One. 2018;13(5):e0197696.

11. Morrison CS, Wang J, Van Der Pol B, Padian N, Salata RA, Richardson BA. Pregnancy and the risk of HIV-1 acquisition among women in Uganda and Zimbabwe. AIDS. 2007;21(8):1027-34.

12. Gray GE, McIntyre JA. HIV and pregnancy. BMJ. 2007;334(7600):950-3.

13. Mugo NR, Heffron R, Donnell D, Wald A, Were EO, Rees $\mathrm{H}$, et al. Increased risk of HIV-1 transmission in pregnancy: a prospective study among African HIV-1-serodiscordant couples. AIDS. 2011;25(15):1887-95.

14. Rathore S, Jamwal A, Gupta V. Herpes simplex virus type 2: seroprevalence in antenatal women. Indian J Sex Transm Dis AIDS. 2010;31(1):11-5.

15. Diclemente RJ, Wingood GM, Crosby RA, Rose E, Lang D, Pillay A, et al. A descriptive analysis of STD prevalence among urban pregnant AfricanAmerican teens: data from a pilot study. J Adolesc Health. 2004;34(5):376-83.

16. Johnson HL, Ghanem KG, Zenilman JM, Erbelding EJ. Sexually transmitted infections and adverse pregnancy outcomes among women attending inner 
city public sexually transmitted diseases clinics. Sex Transmit Dis. 2011;38:167-71.

17. Johnson PJ, Hellerstedt WL. Current or past physical or sexual abuse as a risk marker for sexually transmitted disease in pregnant women. Perspect Sex Reprod Health. 2002;34:62-7.

18. Sutton M, Sternberg M, Koumans EH, McQuillan G, Berman S, Markowitz L. (2007). The prevalence of Trichomonas vaginalis infection among reproductive-age women in the United States, 20012004. Clin Infect Dis. 2007;45:1319-26.

19. Satterwhite CL, Gray AM, Berman S, Weinstock H, Kleinbaum D, Howards PP. (2012). Chlamydia trachomatis infections among women attending prenatal clinics: United States, 2004-2009. Sex Transmit Dis. 2012;39:416-20.

20. Wheeler R, Earnshaw VA, Kershaw T, Ickovics JR. Postpartum sexually transmitted disease: Refining our understanding of the population at risk. Sex Transmit Dis. 2012;39:509-13.

21. Kekki M, Kurki T, Kotomäki T, Sintonen $H$, Paavonen J. Cost-effectiveness of screening and treatment for bacterial vaginosis in early pregnancy among women at low risk for preterm birth. Acta Obstet Gynecol Scand. 2004;83(1):27-36.

22. Cotch MF, Hillier SL, Gibbs RS, Eschenbach DA. Epidemiology and outcomes associated with moderate to heavy Candida colonization during pregnancy. Vaginal Infections and Prematurity Study Group. Am J Obstet Gynecol. 1998;178(2):374-80.

23. Andrews WW, Goldenberg RL, Mercer B, Iams J, Meis P, Moawad A, et al. The preterm prediction study: association of second-trimester genitourinary chlamydia infection with subsequent spontaneous preterm birth. Am J Obstet Gynecol. 2000;183(3):662-8.

24. Kiss H, Petricevic L, Husslein P. Prospective randomized controlled trial of an infection screening programme to reduce the rate of preterm delivery. BMJ. 2004;329(7462):371.

Cite this article as: Chaubey S, Melhotra R, Sharma $\mathrm{U}$. Prevalence of sexually transmitted infections among pregnant women with known HIV status and their perinatal outcome- a retrospective single centre analysis. Int J Reprod Contracept Obstet Gynecol 2021;10:1602-7. 